www.jmscr.igmpublication.org

Impact Factor 5.84

Index Copernicus Value: 71.58

ISSN (e)-2347-176x ISSN (p) 2455-0450

crossref DOI:_https://dx.doi.org/10.18535/jmscr/v5i11.160

Journal Of Medical Science And Clinical Research

\title{
Changing the Paradigm of Breast Abscess Management-Ultrasound Aspiration and Suction Drain versus Incision and Drainage in Treatment of Breast Abscess
}

\author{
Authors \\ Dr Suhail Masood Khan, Dr Azhar Ajaz Khan, Dr Anzeen Nazir Kanth, \\ Dr Aymen Masood Khan, Dr Irtifa Nazir Kanth
}

\begin{abstract}
An acute inflammatory lump which yields pus on incision/aspiration is broadly termed as a breast abscess. It is highly related to pregnancy and caused when a child feeds leading to nipple piercing and bacterial colonization due to improper nursing technique and incomplete emptying of the breast. Breast abscess remains a morbid condition among lactating women in developing countries as compared to the women in developed countries due to improved puerperal hygiene, nutrition, early administration of antibiotics and standard of living. Breast abscess ranges from mastitis to deep abscess and is the most common cause of morbidity in puerperal women. In India the Incidence of lactation breast abscess is very high. This study aims to compare the results of ultrasound guided aspiration of abscess and incision and drainage in the management of breast abscess. This is a comparative study between ultrasound guided aspiration of abscess and incision and drainage consisting of 120 patients who underwent both the treatment modalities alternatively. Ultrasound guided aspiration is an effective method of treatment in breast abscess with a good patient satisfaction and less morbidity.

Keywords: Breast abscess, USG guided aspiration, hypoechoic lesion.
\end{abstract}

\section{Introduction}

Breast when infected may present as a localized phenomenon or as part of a systemic illness. Breast abscess is one of the commonest form of surgical emergencies usually seen in lactating women. ${ }^{1,2}$ The frequency of breast abscess is highly related to pregnancy and of the main causes are nipple piercing by a child during feeding and bacterial colonization due to improper nursing technique and incomplete emptying of the breast. $^{3,4}$ Prompt diagnosis and management is necessary if breast feeding is to be continued and for the prevention of further complications. ${ }^{5}$
Treatment of breast abscesses is a difficult clinical problem. ${ }^{6}$ In the initial stages, acute mastitis may be treated by the use of appropriate antibiotics. Once an abscess is established, conventional management usually involves incision and drainage by providing either general or regional anaesthesia; however this is associated with regular dressing, prolonged healing time, and difficulty in breast feeding, possible unsatisfactory cosmetic outcome, rupture and recurrent breast abscess. ${ }^{7}$ Hence now-a-days treatment of breast abscess by repeated needle aspiration with or without ultrasound guidance has gained its 
importance. 8 This procedure has been used successful and is associated with less recurrence, excellent cosmetic result and has less costs. ${ }^{10}$ This study intends to compare the outcome and effectiveness two methods- invasive method i.e., conventional incision \& drainage and minimally invasive procedure i.e., ultrasound guided aspiration/repeated aspiration in the treatment of breast abscess with reference to complications like post operative pain, residual abscess, duration of hospital stay, time required for complete healing and appearance of scar.

\section{Aims and Objectives}

To compare management of breast abscess by incision and drainage $\mathrm{v} / \mathrm{s}$ ultrasound guided aspiration/repeated aspiration with reference to -

1. Post operative pain

2. Time required for complete healing

3. Duration of hospital stay

\section{Material and Methods}

A comparative study was carried out in department of general and minimal access surgery in a tertiary health care centre, Sher E Kashmir Institute of Medical Sciences for the period of 2 years (February 2015- February 2017) after taking approval from institutional ethical committee of the institution for the study. Within the defined study period data was collected from all patients attending the surgical outpatient department with pain and swelling over the breast/s. Total no of 120 female patients of age between 18-65 years and diagnosed breast abscess with abscess size of less than $10 \mathrm{~cm}$ in diameter on ultrasonography were included in the study after taking due written consent form. For one group of patients (group A) which included 60 patients, under short General anaesthesia with aseptic precautions, incision and drainage done with 11 no blade and abscess cavity packed with Wick gauze. For other group of patients (group B) which included 60 patients, under Local anaesthesia with Ultrasound guidance, aspiration done with $16 \mathrm{G}$ needle with Compressive bandage done. In USG guided aspiration, Patients will be followed up in 7 th and $14^{\text {th }}$ day following the procedure.

Exclusion criteria included

- patients of age $<18$ or $>65$ years,

- suspicious lesions/malignancy especially inflammatory carcinoma of breast,

- immunocompromised,

- recurrent breast abscess, ruptured abscess, tuberculosis and

- Complicated breast abscess presenting with skin changes, ulceration, necrosis and gangrenous abscess.

The patients were diagnosed clinically for duration, site, nature and past history of abscess. General examination including pulse rate, blood pressure and body temperature were recorded. Detailed examination of breasts was carried including increased temperature, tenderness, and discharge from the nipple, fluctuation and axillary lymphadenopathy. Blood investigation for total leucocytes count was made.

\section{Results}

A total of 120 patients were included in our study. All patients were age of the cases ranging from 18-42 years with average being 23.93 years among group A which was comparable to 23.20 years among group B and the difference was statistically not significant as shown in Figure1 (range 18-42 years).

Figure 1: Age distribution of breast abscess.

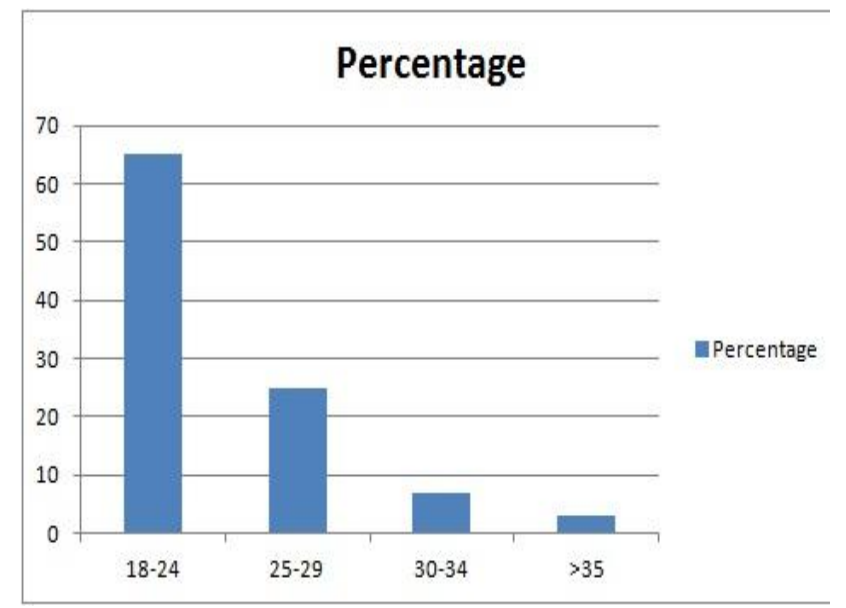

Mean parity distribution was compared between the two groups. $66.7 \%$ cases in group A were primipara, which was more as compared to $56.7 \%$ 
of the cases among group B, but difference was not statistically significant.

Figure 2 Comparison of mean parity distribution between two groups.

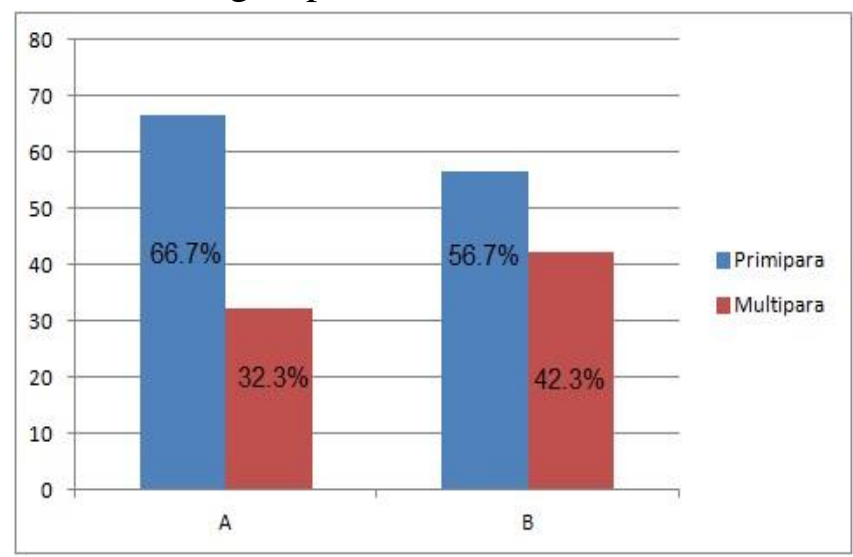

The breast abscess was divided in to four peripheral quadrants and sub areolar on either side. Table no 2 reveals that the distribution of breast abscess was more on the left side $72(60 \%)$ than on the right side $48(40 \%)$ and also we observed that left upper and outer quadrant abscesses were most common amongst all the abscesses (40\%).

Table:-1 Distribution of breast abscess according to quadrants in the study

\begin{tabular}{|l|c|c|}
\hline $\begin{array}{l}\text { Site of abscess } \\
\text { (quadrant) }\end{array}$ & left $(\mathrm{n}=72)$ & Right $(\mathrm{n}=48)$ \\
\hline Upper and outer & 48 & 30 \\
\hline Lower and outer & 12 & 8 \\
\hline Lower and inner & 4 & 6 \\
\hline Lower and outer & 6 & 4 \\
\hline Sub areolar & 2 & 0 \\
\hline
\end{tabular}

By the time of treatment $90 \%$ of the cases were lactating and non-lactating are $10 \%$ in both the groups hence the difference was not significant as in Table 2

Table:-2 Distribution of patients according to lactational status $(n=120)$

\begin{tabular}{|l|c|c|}
\hline Lactation status & Number & Percentage \\
\hline Lactational & 108 & 90 \\
\hline Non- Lactational & 12 & 10 \\
\hline Total & 120 & 100 \\
\hline
\end{tabular}

In our study overall 120 patients, all patients complained of pain and tenderness 112 patients complained of swelling, 90 patients have fever and 86 patients have erythema.

Table:-3 Data of clinical features of breast abscess in the study

\begin{tabular}{|l|c|c|}
\hline Clinical features & Frequency & Percentage \\
\hline Pain & 120 & $100 \%$ \\
\hline Swelling & 112 & $93 \%$ \\
\hline Fever & 90 & $75 \%$ \\
\hline Tenderness & 120 & $100 \%$ \\
\hline Erythema & 86 & $72 \%$ \\
\hline
\end{tabular}

Table No. 4: Showing comparison of post-treatment pain between incised (Group A) and aspirated group (Group B) (n=120)

\begin{tabular}{|c|c|c|c|c|c|c|c|c|}
\hline \multirow{2}{*}{$\begin{array}{l}\text { Post- } \\
\text { treatment } \\
\text { pain }\end{array}$} & \multicolumn{2}{|c|}{ Group A $(n=60)$} & \multicolumn{2}{|c|}{ Group B $(n=60)$} & \multicolumn{2}{|c|}{ Total } & \multirow{2}{*}{$\begin{array}{c}\begin{array}{c}\text { Chi- } \\
\text { square }\end{array} \\
8.53\end{array}$} & \multirow{2}{*}{$\frac{\text { P-value }}{0.003}$} \\
\hline & Number & $\%$ & Number & $\%$ & 120 & $\%$ & & \\
\hline Present & 6 & 20 & 34 & 56.67 & 46 & 38.33 & & \\
\hline Absent & 24 & 80 & 26 & 43.33 & 74 & 61.67 & & \\
\hline
\end{tabular}

Pain was present in $20 \%$ of patients in incised group, whereas $56.67 \%$ in aspirated group. The difference was statistically significant $(\mathrm{p}=0.003)$. 
Figure 3: Showing comparison of post-treatment pain between incised (Group A) and aspirated group (Group B) ( $\mathrm{n}=120)$

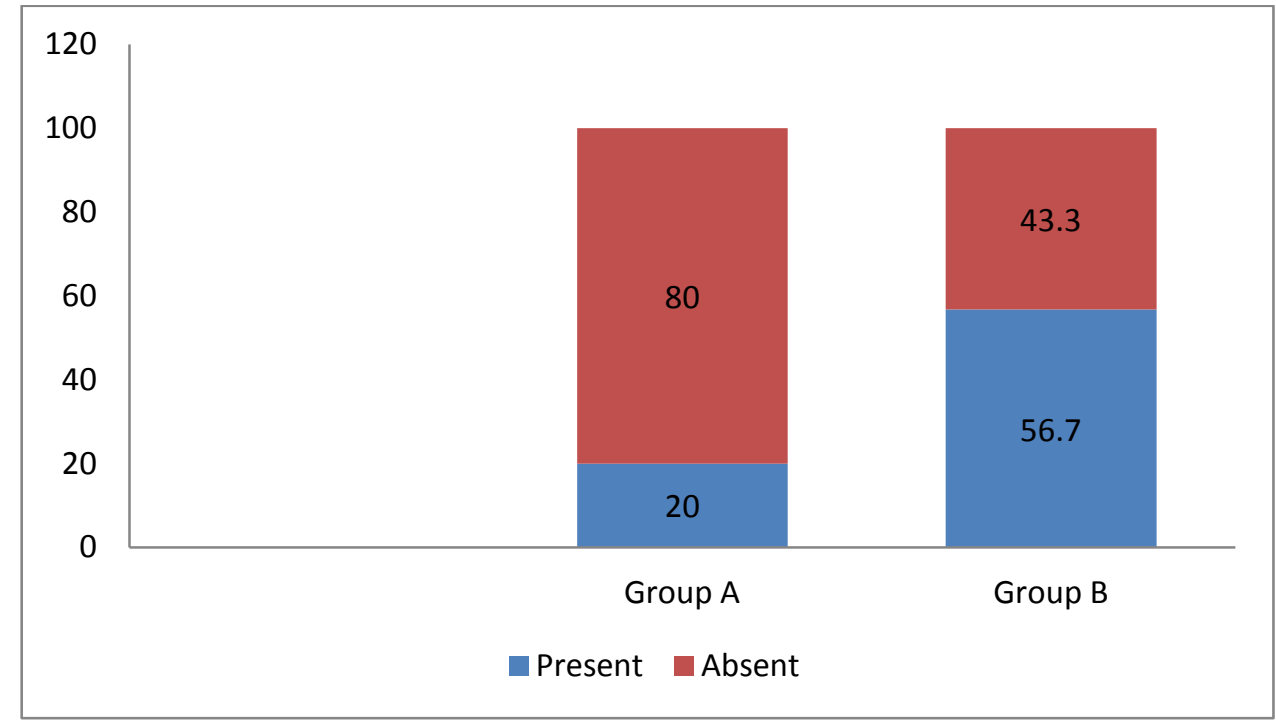

Table No 4: Showing comparison of post-treatment pain between incised and aspirated group ( $\mathrm{n}=120)$

\begin{tabular}{|c|c|c|c|c|c|c|c|c|}
\hline \multirow{2}{*}{$\begin{array}{l}\text { Healing time(in } \\
\text { days) }\end{array}$} & \multicolumn{2}{|c|}{ Group A } & \multicolumn{2}{|c|}{ Group B } & \multicolumn{2}{|c|}{ Total } & \multirow{3}{*}{$\begin{array}{c}\text { Chi-square } \\
43.5294\end{array}$} & \multirow{7}{*}{$\begin{array}{l}\text { P-value } \\
0.0001\end{array}$} \\
\hline & Number & $\%$ & Number & $\%$ & Number & $\%$ & & \\
\hline $1-5$ & 0 & 0 & 12 & 20 & 12 & 10 & & \\
\hline $6-10$ & 0 & 0 & 28 & 46.67 & 28 & 23.3 & & \\
\hline $11-15$ & 14 & 23.33 & 20 & 33.33 & 34 & 28.34 & & \\
\hline $16-20$ & 28 & 46.67 & 0 & 0 & 28 & 23.33 & & \\
\hline $21-25$ & 18 & 30.0 & 0 & 0 & 18 & 15.0 & & \\
\hline
\end{tabular}

Figure 4: Showing comparison of post-treatment pain between incised and aspirated group $(\mathrm{n}=120)$

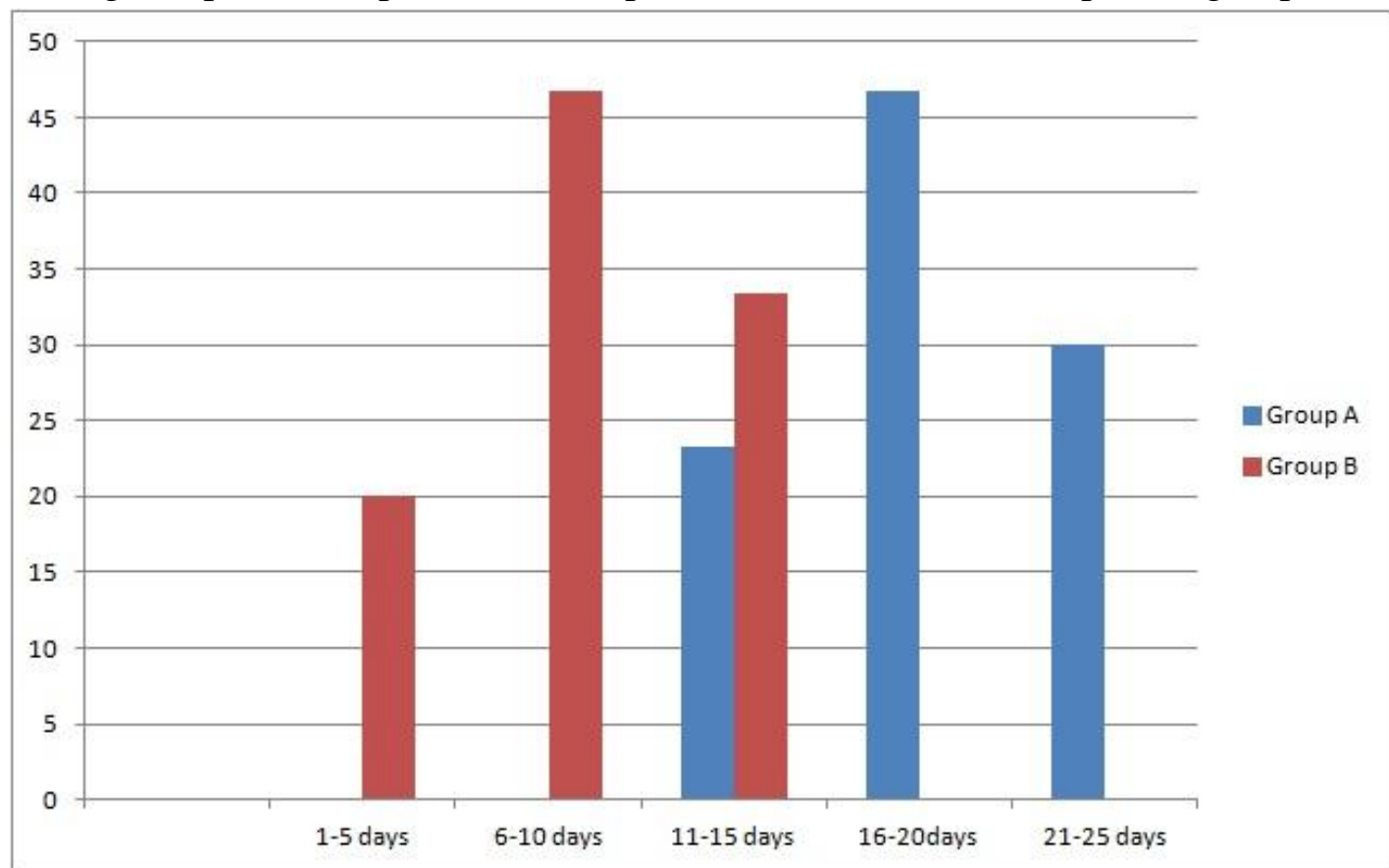

Most cases of aspirated group, $46.67 \%$, healed between 6-10 days; whereas majority of incised group, $46.67 \%$, healed between 16-20 days. The healing period of incised group was 11-25 days, mean $=18.67(+/-3.96)$ days. The healing period of aspirated group was 3-7 days, mean $=8.33(+/-$ $2.09)$ days. The difference is statistically significant, p-value $<0.0001$. 
Table 5: Comparison of cosmetic outcome between two groups

\begin{tabular}{|l|c|c|c|c|}
\hline \multirow{2}{*}{ Outcome } & \multicolumn{2}{|c|}{ Group A } & \multicolumn{2}{c|}{ Group B } \\
\cline { 2 - 5 } & Number & $\%$ & Number & $\%$ \\
\hline Scar & 60 & 100 & 8 & 13.3 \\
\hline No Scar & 0 & 0 & 52 & 86.7 \\
\hline
\end{tabular}

Figure 5: Comparison of cosmetic outcome between two groups

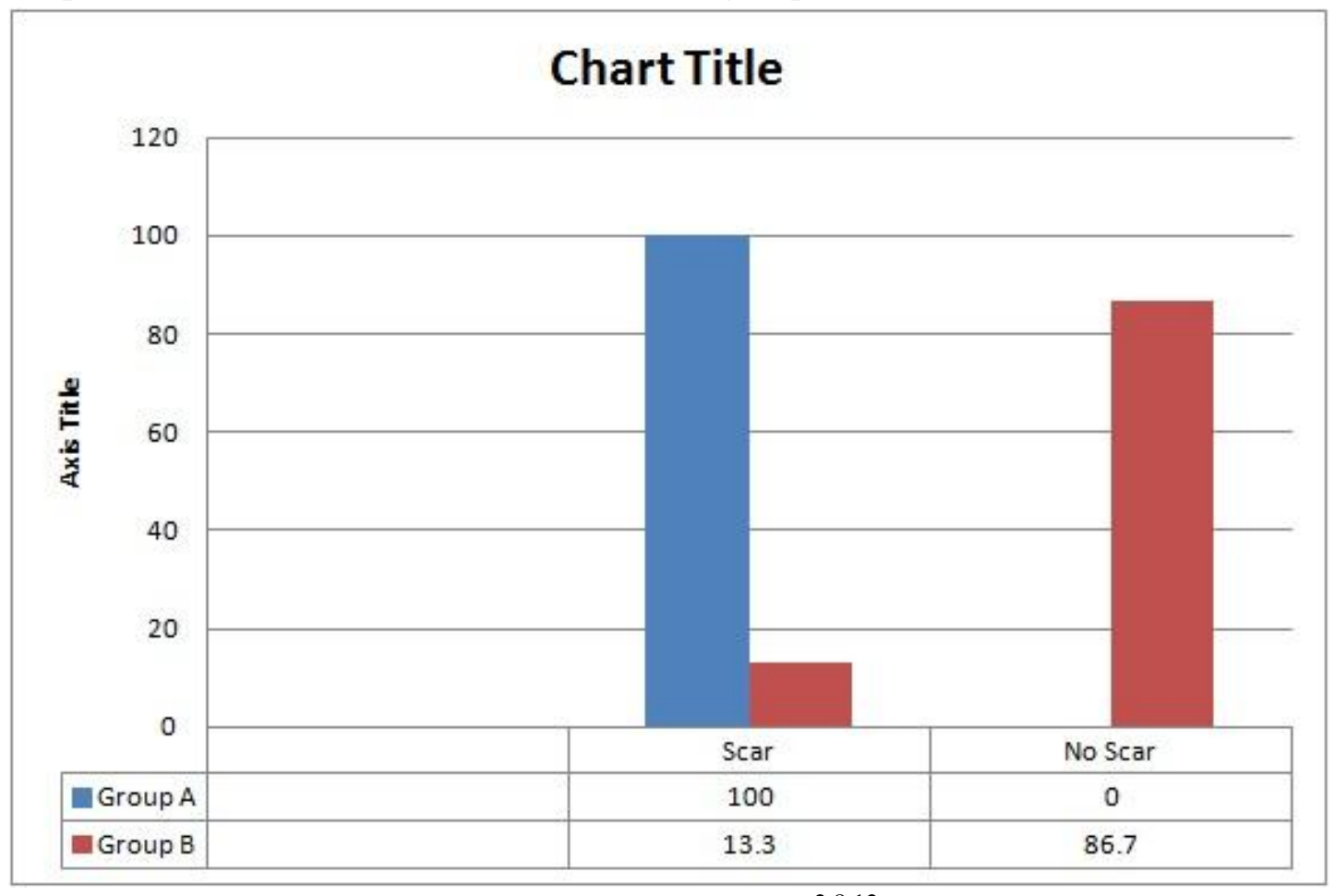

Cosmetic outcome was assessed at the time of years. ${ }^{2,8,12}$.Although breast abscess generally has follow up after the abscess was completely healed. The outcome was assessed as patients having scar over the breast or not and overall patients satisfaction as shown in table 5 and difference between the groups were significant with each other $(\mathrm{p}=0.001)$.

\section{Discussion}

In our comparative study, we compared two groups which were divided on the basis of treatment received by each group; one group was treated with aspiration and the other by incision and drainage of the breast abscess without control group. Our study had $90 \%$ lactation patients which is comparable with the findings in the series of Schwarz et al. ${ }^{11}$ which had $83 \%$ (lactational) and $17 \%$ (non-lactational). In our current report, patients age range has some similarity with the results of Dixon et al and Dener et al, who demonstrated that breast abscesses most commonly affects women aged 18-50 been associated with mastitis and breast feeding, the results of our study and others indicate that abscess was also found in non-lactating women Crowe et al and Scholefield et al. ${ }^{13}$ Breast abscess is frequently located in the upper and outer quadrant, which fits with the fact that most of the breast parenchyma is located in this quadrant.15 In our study, $65 \%$ of breast abscess was found in the upper and outer quadrant and $60 \%$ of breast abscess was located in the left breast. This is in agreement with Eryilmaz et al and Chandika et al reported a similar incidence of breast abscess over left side and abscess in the upper and outer quadrant. ${ }^{14,15}$ In our study finding of peripherally located abscess more than centrally locating was consistent with the results of Hamid et al. ${ }^{16}$ In 1995 crowe dj et al $^{13}$ reported 21 patients presented with clinical abnormalities, including palpable mass $(20 ; 95 \%)$, pain $(11 ; 52 \%)$, erythema $(11 ; 52 \%)$, warmth $(7 ; 33 \%)$, skin thickening or fixation $(4 ; 19 \%)$. In 2003 leborgne $\mathrm{f}$ 
et $\mathrm{al}^{17}$ published report of 73 patients, among them only $12 \%$ were associated with fever, all patients had a palpable mass; in $80 \%$ the mass was painful, and in $71 \%$ the overlying skin was red. In our study $100 \%$ patients had pain, with swelling in $92.8 \%$ but $75.71 \%$ patients had fever; $100 \%$ patients had raised temperature, local tenderness and $72.8 \%$ had erythema. These findings were also comparable with them.

In our study all the patient's underwent ultrasonography to assess the size and location of breast abscess and to confirm the diagnosis of breast abscess, though it was diagnosed clinically. Ultrasonography was also useful tool in diagnosis of breast abscess as found in study done by Dener et al. ${ }^{8}$ Clinical symptoms after the procedure like pain and fever were assessed in the patients of breast abscess treated with aspiration and with incision and drainage. At the end of day 10, we observed $96.7 \%$ of the patients in aspirated group got relief from pain whereas in the incised group 93.3\% of the cases had no pain and the difference was not found to be significant. It was also found that wound healing was significantly faster in the aspirated group than in the incised group (4.3 days versus 7.7 days); this finding was similar to the study done by Eryilmaz et al. ${ }^{14}$

In their retrospective study that includes 39 patients, juan $\mathrm{d}$ et al.showed that percutaneous drainage procedures in breast abscesses are a safe and effective alternative to incision and drainage $^{18}$. After reviewing 36 papers, thirumalaikkumar et al. concluded that the smaller the abscesses are, the better the outcome is and the lower the recurrence rate is following the aspiration $^{19}$.

In the present study the cosmetic outcome was evaluated according to patient's satisfaction and scar mark. Patients underwent with aspiration, were satisfied with the cosmetic outcome, as there were no scars present after the treatment as similar to the studies of Singh et al and Kastrup et al. ${ }^{20,21}$

\section{Conclusion}

Breast abscess is a predicament that has afflicted the women through the ages and is still prevalent especially among the lactating mothers and their babies who require continued breast feeding. Historically, most patients with a lactating abscess have been treated by incision and drainage of the abscess under general anaesthesia. These may cause considerable distress to both the mother and baby and the final cosmetic result is often unsatisfactory.

The observation of our study reveals that needle aspiration of the abscess with ultrasonographic guidance combined with antibiotics has a great value in the treatment of breast abscess even in abscess with large volume; although repeated aspiration may be needed to obtain complete resolution, this therapy is a well-accepted alternative to surgical treatment. It does not require any mode of anaesthesia and can be done on out-patient department basis. Breast abscess in selected group of patients with diameter of less than $7 \mathrm{~cm}$ can be treated by aspiration successfully and with a good cosmetic outcome. Now, majority of the breast abscess can be effectively managed without surgery on an outpatient basis, by a combination of ultrasound guided needle aspiration and antibiotics with better cosmetic satisfaction.

\section{References}

1. Martin JG. Breast abscess in lactation. Journal of midwifery and women's health. 2009; 54(2):150-1.

2. Ulitzsch D, Nyman MK, Carlson RA. Breast abscess in lactating women: USguided treatment. Radiology. 2004; 232(3):904-9.

3. Leibman AJ, Misra M, Castaldi M. Breast abscess after nipple piercing: sonographic findings with clinical correlation. Journal of ultrasound in medicine. Official journal of the American Institute of Ultrasound in Medicine. 2011; 30(9):1303-8. 
4. Kaufmann R, Foxman B. Mastitis among lactating women: occurrence and risk factors. Social sciences in medicine. 1991; 33(6):701-5).

5. Cignacco E, Zbinden A, Surbek D. Ongoing breastfeeding with breast abscess.Pflege.2006; 19(2):70-8.

6. Rassmussen NR, Bilchet-Toft M.Primary periareolar abscess in the Non-lactating breast risk of recurrence. AMJ Surg. 1987; 153:571-3.

7. Benson EA. Management of breast abscesses. World J Surg. 1989; 13:753-6.)

8. Dener $\mathrm{C}$, Inan A. Breast abscesses in lactating women. World J Surg. 2003; 27:130-3.

9. Elagili F, Abdullah N, Fong L, Pei T. Aspiration of breast abscess under ultrasound guidance: outcome obtained and factors affecting success. Asian journal of surgery/Asian Surgical Association. 2007; 30(1):40-4.

10. Srauss A, Middendorf K, Müller-Egloff S, Heer IM, Untch M, and Bauerfeind I.Sonographically guided percutaneous needle aspiration of breast abscesses-a minimal invasive alternative to surgical incision. Ultraschall Med. 2003; 24(6): 393-8.

11. Schwarz rj, shrestha $r$. Needle aspiration of breast abscesses. Am j surg 2001;182: 117? 119

12. Dixon JM. Repeated aspiration of breast abscesses in lactating women. BMJ (Clinical research ed).1988;297(6662): 1517-8

13. Crowe DJ, Helvie MA, Wilson TE. Breast infection. Mammographic and sonographic findings with clinical correlation. Investigative radiology.1995;30(10):582-7
14. Eryilmaz R, Sahin M, Hakan Tekelioglu M, Daldal E. Management of lactational breast abscesses. Breast (Edinburgh, Scotland). 2005; 14(5):375-9.

15. Chandika AB, Gakwaya AM, KiguliMalwadde E, Chalya PL. Ultrasound guided needle aspiration versus surgical drainage in the management of breast abscesses: a Ugandan experience. BMC research notes. 2012; 5:12.

16. Hamid HS, Osama MI. Percutaneous Needle Aspiration Is A Minimally Invasive Method For A Breast Abscess. Arch Clin Exp Surg. 2012;1(2):105-9

17. Leborgne $f$, leborgne $f$. Treatment of breast abscesses with sonographically guided aspiration, irrigation and instillation of antibiotics. Ajr am j roentgenol 2003;181:1089-9

18. Berna-serna JD, madrigal $\mathrm{m}$, berna-serna jd. Percutaneous management of breast abscesses. An experience of 39 cases. Ultrasound med biol 2004; 30:1-6.

19. Thirumalaikumar s, kommu s. Best evidence topic reports. Aspiration of breast abscesses. Emerg med j 2004; 21:333-334.

20. Singh G, Singh G, Singh LR, Singh R, Singh S,Sharma KL. Management of breast abscess by repeated aspiration and antibiotics. Journal of Medical Society. 2012; 26(3):189.

21. Karstrup S, Solvig J, Nolsoe CP, Nilsson P, KhattarS, Loren I, et al. Acute puerperal breast abscesses: US-guided drainage. Radiology. 1993;188(3):807-9\} 